\title{
IDSA Releases Updated Coccidioidomycosis Guidelines
}

The Infectious Diseases Society of America (IDSA) has released updated Guidelines for the Treatment of Coccidioidomycosis, also known as cocci or Valley Fever (1). Coccidioidomycosis is a fungal infection endemic to the southwestern United States and a common cause of pneumonia and pulmonary nodules in this area. However, the infection can disseminate systemically especially in immunocompromised hosts and certain ethnic populations resulting in a variety of pulmonary and extrapulmonary complications. In addition to recommendations for these complications, the new guidelines address management of special at-risk populations, preemptive management strategies in at-risk populations and after unintentional laboratory exposure. The guidelines also suggest shorter courses of antibiotics for hospitalized patients and more ambulatory treatment for most individuals who have contracted Valley Fever.

The panel was led by John N. Galgiani, MD, director of the Valley Fever Center for Excellence at the University of Arizona Health Sciences. Galgiani led a panel of 16 experts including faculty from the University of Arizona, Mayo Clinic Arizona, University of California San Diego, University of California Los Angeles, Utah, Barrows Neurological Institute and the University of Utah.

A reference booklet, "Valley Fever (Coccidioidomycosis)—Tutorial for Primary Care Physicians," from the UA Valley Fever Center for Excellence complements the guidelines and is available through the Southwest Journal of Pulmonary and Critical Care (2) and also available at the Valley Fever Center for Excellence website.

The guidelines begin with a disclaimer that it is "important to realize that guidelines cannot always account for individual variation among patients and ... not intended to supplant physician judgment". This is especially important because many of the guidelines are based on expert opinion rather than strong scientific evidence.

\section{References}

1. Galgiani JN, Ampel NM, Blair JE, Catanzaro A, Geertsma F, Hoover SE, Johnson RH, Kusne S, Lisse J, MacDonald JD, Meyerson SL, Raksin PB, Siever J, Stevens DA, Sunenshine R, Theodore N. 2016 Infectious Diseases Society of America (IDSA) clinical practice guideline for the treatment of coccidioidomycosis. Clin Infect Dis. 2016 Sep 15;63(6):e112-46. [CrossRef] [PubMed]

2. Galgiani JN. Valley fever (coccidioidomycosis): turtorial for primary care physicians. Southwest J Pulm Crit Care. 2015;10(5):265-88. [CrossRef] 